\title{
Analysis of Factors Influencing Smallholder Farmers' Participation in Non-Farm Employment Activities and Their Impact on Households' Food Security: The Case of Mbire District, Mashonaland Central Province of Zimbabwe
}

\author{
Misheck Tussle Mundowa* Clever Mumbengegwi \\ Department of Economics, University of Zimbabwe, PO Box MP 167, Mt Pleasant, Harare, Zimbabwe
}

\begin{abstract}
This study investigates the factors influencing smallholder farmer's decision to participate in non-farm employment activities and its impact on rural households' food security status in the Mbire District of Zimbabwe. The analysis uses a treatment evaluation model and the associated propensity score matching (PSM) technique, which permits the comparison between the food security status of smallholder farmers who participate in nonfarm employment activities and those who do not. Estimation of propensity scores enable us to identify the factors influencing smallholder farmers' decision to diversify into non-farm employment activities. The results indicate that a number of demographic (gender and education of household head), infrastructural (internet access and distance to the main road) and farm level characteristics (land size, livestock herd owned and productive assets) have qualitative and quantitatively different impacts on rural households' participation in non-farm employment activities. Further, the empirical analysis confirms that diversifying into non-farm employment activities improves rural households' food security status. The results imply that non-farm employment activities can be a way out of food insecurity in Mbire district. The study therefore recommends the government and NGOs to induce the rural households to diversify into non-farm activities as they improve their food security status since the climatic conditions in the district are not well suitable for agricultural practices.
\end{abstract}

Keywords: Non-farm employment; Propensity Score Matching (PSM); rural household food security; Mbire district of Zimbabwe

DOI: $10.7176 / \mathrm{JESD} / 11-22-06$

Publication date: November $30^{\text {th }} 2020$

\section{Introduction}

One of the major public policy challenges facing Sub-Sahara Africa (SSA) is feeding its growing population and alleviating food insecurity, especially among rural farm households (Owusu et al., 2011). Participating in nonfarm employment activities ${ }^{1}$ is one of the most widespread coping strategies used to combat food insecurity by food-deficit rural farm households. The factors influencing the choice to participate and the implications of this participation on food security are not altogether known. Some strands of literature suggest that non-farm employment activities improve rural households' incomes and food security (Mishra and Rahman, 2018; Seng, 2015; Shehu and Sidique, 2013), while others suggest that it has no or even negative effects (Pfeiffer et al., 2009; Kinuthia et al., 2018). Knowledge of these factors would help inform policy makers to identify those rural households most vulnerable to food insecurity and to design more accurately targeted policy interventions. The study seeks to evaluate the impact of participation in non-farm employment activities on food security ${ }^{2}$.

Mbire district is located in the low-lying mid-Zambezi valley forming part of agro-ecological regions $4^{3}$ and $5^{4}$, which makes it unsuitable for food crop production due to its high temperatures and low and unpredictable rainfall patterns (Fritz et al., 2003). As a result, Mbire is one of the four out of sixty rural districts of Zimbabwe experiencing high levels of food insecurity; with between 39 and 42 per cent of households being food insecure (Zimbabwe Vulnerability Assessment Committee (ZimVAC), 2018). Despite the poor climatic conditions, which does not support crop production, the government of Zimbabwe, like other governments in developing countries, is trying to combat food insecurity in the district through agricultural input provision, which is bringing no impact on households' food security. The study therefore assesses if participation in non-farm employment activities could be a coping strategy to food insecurity in the semi-arid parts of Zimbabwe and other developing countries as they do not afford to install irrigation facilities.

Most studies in the food security literature used more subjective food security measures that only captures

\footnotetext{
1. Any gainful employment sought by the family labourer off the household farm, which include fishing, trading, construction, transport, agro-processing and gold panning (Tran et al., 2015).

2. Exists when all people, at all times, have physical and economic access to sufficient, safe and nutritious food that meets their dietary needs and food preferences for an active and healthy life (World Food Summit, 1996).

${ }^{3}$. Receiving $450-600 \mathrm{~mm}$ rainfall per year. Subject to frequent seasonal droughts.

4. Receiving normally less than $500 \mathrm{~mm}$ rainfall per year, very erratic and unreliable. Northern Lowveld may have more rain but topography and soils are poorer.
} 
the physical access (food availability) aspect and ignores the economic access aspect in food security definition. This study adapted the food security measure suggested by Coates et al. (2007), which measure food security in terms of the number of times when at least one member of a household had fewer meals a day than normal ${ }^{1}$ due to lack of food accessibility. This improved and less subjective food security measure captures both the physical and economic access aspects of food security, which is very important according to Sen (1982).

More specifically, this study attempts to investigate the factors influencing the rural farm households' choice to participate in non-farm employment activities in Mbire district of Zimbabwe and determine its impact on food security. This will invariably lead to the acceptance or rejection of the null hypothesis that participation in non-farm employment activities has a positive impact on rural households' food security. The quantification of the factors influencing rural farm households' participation in non-farm employment activities is addressed by employing the logit model, while the impact is determined by applying the Propensity Score Matching (PSM) technique and the treatment evaluation model, which allows for the comparison of the food security status of the participants and non-participants. The study uses the cross sectional data collected via structured questionnaires from the sample selected from Mbire district.

\section{Conceptual Framework}

Lewis (1954) and Fei and Ranis' (1964) dualism models postulated the coexistence of both the industrial (nonfarm) sector and the backward sector (agriculture) in developing countries. The marginal productivity of labour in the industrial sector (wage rate, $w_{2}$ ) is assumed to be higher than that in the agricultural sector $\left(w_{1}\right)$. This positive wage differential $\left(w_{2}-w_{1}>0\right)$ act as an incentive to lure the rural smallholder farmers to participate in employment activities in the non-farm sector where they earn higher incomes and have their households' wellbeing and food security status improved. However, these marginal productivities of labour that influence rural smallholder famers' decision to participate in non-farm employment activities are not directly observable. What is only observable is whether the household has participated in non-farm employment activities or not, hence the latent variable (decision to participate) can be modeled using the index functions and the binary response models (Cameron and Trivedi, 2007). It is therefore assumed that the rural smallholder farmer can only participate in non-farm employment activities $\left(L_{i}=1\right.$ ) if there exist a positive wage differential (i.e $w_{2}>w_{1}$ ) and does not participate $\left(L_{i}=0\right)$ if $w_{2} \leq w_{1}$. According to Singh et al. (1986), the wage differential between the non-farm sector and the agricultural sector is influenced by the demographic characteristics of the smallholder rural farm household, infrastructural characteristics of the location of the rural smallholder farm household and some farm level characteristics, which will be used in this study.

\section{Methodology and Model Specification}

\subsection{Empirical Model on Non-Farm Employment Participation}

Since the dependent variable (participate $=1,0$ if otherwise) on the participation model is binary rather than continuous, linear estimation techniques (e.g. Ordinary Least Squares or Linear Probability Model) yields biased results. Linear estimation techniques may yield negative variance of the error term and the probabilities may lie outside the reasonable range of between zero and one. Therefore, the Maximum Likelihood Estimation (MLE) techniques (e.g. Probit and Logit) are more appropriate to quantify the factors influencing the rural farm households'2 decision to participate in non-farm activities (Cameron and Trivedi, 2009). According to Amemiya (1985), the Probit and logit models yield quantitatively similar results where $\hat{\beta}_{\text {logit }}=1.6 \hat{\beta}_{\text {probit }}$ or $\hat{\beta}_{\text {logit }}=1.8 \hat{\beta}_{\text {probit }}$ when the data are centered on the mean or zero respectively, hence the choice between the probit and the logit models doesn't matter. The current study will employ the logit model to answer the first study research question to identify factors that influence rural farm households' involvement in non-farm activities.

We can model the rural farm households' decision to participate in non-farm activities using the index functions and the logit model since we cannot observe the wage differential between the farm and non-farm sector. What can only be observed is whether the farmer works in the non-fam sector or not. The model in equation (1) gives the index function:

$$
\begin{aligned}
L_{i}^{*} & =\beta^{\prime} Z_{i}+\xi_{i} \\
L_{i} & =1_{\text {if }} L_{i}^{*}>0 \\
L_{i}=0 & \text { if } L_{i}^{*} \leq 0
\end{aligned}
$$

Where $L_{i}^{*}$ is the latent (unobservable) variable, which is the wage differential between the farm and the non-farm

\footnotetext{
${ }^{1}$. According to Nyamwanza (2014), a typical food secure household in Mbire district have two meals a day.

2. According to the culture of the people in Mbire district, a "household" is defined as "people who live together and share food from a common pot" (Nyamwanza, 2014)
} 
sector, and $\xi_{i}$ is the random disturbance term. The variable $Z_{i}$ is a vector of explanatory variables. The variables in $Z_{i}$ have been informed by the literature. The $Z_{i}$ vector contains the demographic characteristics, which include household head age, household head's gender, consumer-worker ratio ${ }^{1}$ and education level of the household head. It also contains the infrastructural characteristics (distance to the main road, credit access, cellphone ownership, and distance to the nearest market and electricity access) and farm level characteristics (land size, livestock holding and productive assets ownership). The variable $\beta^{\prime}$ is a vector of the coefficients of demographic, infrastructural and farm level characteristic variables. From equation (2), the rural farm household participate $\left(L_{i}=1\right)$ in non-farm employment activities only if the wage differential is positive $\left(L_{i}^{*}>0\right)$ that is if the market wage rate is greater than the reservation wage, otherwise the household does not participate $\left(L_{i}=0\right)$.

Due to Cameron and Trivedi (2009), the farm households' participation decision is modelled as follows: $\operatorname{Prob}\left(L_{i}=1 \mid Z_{i}\right)=\operatorname{Prob}\left(L_{i}^{*}>0 \mid Z_{i}\right)$

$$
\begin{aligned}
& =\operatorname{Prob}\left(\beta^{\prime} Z_{i}+\xi_{i}>0 \mid Z_{i}\right) \\
& =\operatorname{Prob}\left(\xi_{i}>0-\beta^{\prime} Z_{i} \mid Z_{i}\right)
\end{aligned}
$$

with $\xi_{i} \sim f(0,1)$ which is a symmetric probability density function (pdf). This therefore implies that:

$$
\begin{aligned}
\operatorname{Prob}\left(L_{i}\right. & \left.=1 \mid Z_{i}\right)=\operatorname{Prob}\left(\xi_{i}<\beta^{\prime} Z_{i}\right) \\
& =F\left(\beta^{\prime} Z_{i}\right)
\end{aligned}
$$

Equation (5) is the cumulative density function (cdf), which is the probability of success (participate, in this case). Since this study is employing the logistic model, $F$ is the logistic distribution function, which is usually denoted by a Greek letter $\Lambda$, therefore a cumulative density function (cdf) is:

$$
\operatorname{Prob}\left(L_{i}=1 Z^{Z}\right)=\Lambda(X)=\frac{e^{X}}{1+e^{X}}
$$

where: $X=\beta^{\prime} Z_{i}$, and the probability density function (pdf) given by:

$$
\lambda(X)=\beta^{\prime}=\frac{\partial \Lambda(X)}{\partial z}
$$

which is the vector of coefficients of the explanatory variables.

\subsubsection{Definition and Measurement of Variables}

Different variables were expected to influence the farm households' decision to participate in non-farm activities in the study area as informed by both theoretical and empirical literature reviewed. These variables include demographic, infrastructural and farm level characteristics. Demographic characteristics control for personal differences in endowments of skills and innate abilities among rural farm households. Farm level characteristics are a proxy for household wealth (income), which are likely to influence households' decision to participate in the non-farm activities and the infrastructural variables control for the impact of the local environment on the rural farm households' decision to diversify into non-farm employment activities. The variables in the logit model are explained below:

Participation in Non-farm Activities (Part) was the dependent variable in the above specified logit model which is a dichotomous variable, which takes the value of 1 if the household has participated in non-farm activities in the past 12 months from the date of interview, and 0 otherwise. The households who have participated in non-farm activities are expected to be relatively more food secure than the non-participant households as suggested by the literature reviewed.

Age of the Household Head (Hhage) has an important bearing on the farm household head's decision to diversify into non-farm activities as household heads at their young age can probably engage in non-farm activities compared to their old age. However, older household heads might also have the experience and the links that could help them diversify into non-farm activities. Age of the household head is therefore expected to increase/decrease the probability of participating in non-farm employment activities. Tsiboe et al. (2016) used this variable and it was found to have a positive coefficient. This variable was measured in terms of the age of the household head at the time of the interview.

Gender of Household Head (Hhgend) influence a household's decision to participate in non-farm employment activities as men are socially expected to provide for their families. Hence, males are expected to have the higher probability of participating in non-farm activities than their female counterparts. Yesuf (2015) used this variable and found that being male increases the probability of participating in non-farm activities than being female. This variable is dichotomous which takes the value of 1 if the household head is a male, and 0 if otherwise.

Education Level of Household Head (Hheduc) may also influence a household decision to participate in non-farm activities. When an individual acquires more and more education, s/he usually looks for wage

${ }^{1}$ The ratio of the number of the members in a household to the number of household members who actually participate in the fieldwork (Chayanov, 1966). 
employment in the non-farm sector. Hence, the a priori sign of the coefficient of household head's education level is positive. Matshe and Young (2004) used this variable and found it to have a positive effect on the rural farm households' decision to diversify into non-farm activities. This variable is measured in terms of the number of years of schooling after the first 14 years of birth, which is post primary education. This measure was adapted from a study by Matshe and Young (2004).

Distance to the Nearest Market (Dis $m k t$ ) measures the distance in kilometers from the household's home to the nearest market for non-farm products. These areas encourage non-farm activities by acting as centers for commerce. Long distance to the market is a barrier to the participation in non-farm activities, particularly trading. This means that proximity to these places give rise to diversified rural non-farm activities and higher non-farm incomes. The study therefore expected that, the shorter the distance to the market, the higher the probability of a households' participation in non-farm activities. Babatunde and Qaim (2010) used this explanatory variable and found it to reduce the probability of household head's participation in non-farm activities.

Distance to the Main Road (Dis $m r d$ ) measures the distance in kilometers from the household's home to the main road. It is a proxy for the ease with which rural farm household can access the market for their products. The shorter the distance to the main road is, the easier it is for the rural farm households to get access to the markets. The study therefore hypothesized that the longer the distance to the main road, the lower the probability of households' participation in non-farm activities. Tsiboe et al. (2016) used this variable and found that the households who were far away from the main road have a lower chance of participating in non-farm activities.

Livestock Holding (Livstk) is proxied by the total number of cattle owned by a household. Livestock herd play an important role in determining the rural households' decision to participate in non-farm activities. A cattle herd can help boost the households' capital or liquidity by selling it when in need to start up a non-farm enterprise than to approach commercial banks for loans, which increases the farmer's chance to participate in non-farm employment activities. The a priori sign for the coefficient of this variable was a positive sign as found by Yesuf (2015).

Land Size (Landsz) also has an important bearing on the households' decision to participate in non-farm activities. As land size increases, ceteris paribus, the land productivity decreases and then output as well (according to the theory of inverse relationship between farm size and productivity). The study therefore hypothesised a positive correlation between land size and participation in non-farm activities as farm wage (reservation wage) is positively related to marginal land productivity. According to the inverse relationship between farm size and productivity, large farms produce low output per worker; hence, the households participate in non-farm activities to supplement their food and incomes. Tsiboe et al. (2016) used this variable and found its coefficient to have a negative correlation with non-farm participation decision. The variable was measured as the sum of the agricultural and residential land in hectares.

Consumer-Worker Ratio (Conswkr) also influences the households' decision to participate in non-farm activities. Inclusion of this variable is informed by Chayanov (1966) and is measured as the ratio of household size (food consumers in the household) to the number of household members who actually work in the field. The existence of the large number of family members with limited labour resources could have an implication on the decision to participate in non-farm employment activities due to increase in food demand with limited food supply. It is hypothesised that the consumer to worker ratio has a positive impact on the decision to participate in non-farm activities, as the household will be seeking to augment own agricultural food supply with the marketpurchased food.

Productive Assets Ownership (Asset) was used to proxy farmer's wealth and or income. The household assets in Mbire district include ox-drawn ploughs, cars and scotch carts. Assets value eases liquidity constraints to participate in non-farm activities. When the households want capital to start up non-farm enterprises they simply convert their asset to money or approach the banks for loans and use their assets as collateral security. The current study therefore, hypothesised that the farmers who are wealthy have a higher likelihood of engaging in non-farm activities as found by Tran et al. (2015). This variable was measured in terms of the estimated value of the total household productive assets.

Access to Credit to Finance Non-Farm Enterprises (Credt) eases the liquidity constraints faced by the rural smallholder farmers when they want to start non-farm enterprises (or credit can be used to support production activities and hence increase output thus reduced non-farm activities). This increases the likelihood of the households to diversify into non-farm activities. Shehu and Sidique (2013) found that households who had access to credit had a higher chance of participating in non-farm activities in relation to their counterparts, hence improving food security. The households who have access to credit to finance their non-farm enterprises such as trading can easily diversify into non-farm activities. The study therefore expected that the households who have credit access have higher likelihood of participating in non-farm activities than those who have no access to credit. This variable is measured as a dichotomous variable, which takes the value of 1 if the household had accessed credit to finance non-farm activities in the past 12 months, and 0 if otherwise.

Internet Access (Intnet) is now playing an important role in information dissemination, hence the use of this 
variable as one of the core regressors. This is measured as a dummy variable, which takes the value of 1 if the household has access to internet, and 0 otherwise. If the household has access to internet it means that it can easily get access to information on non-farm opportunities through news and social networks such as WhatsApp. Most studies used cellphone ownership as an explanatory variable for the decision to participate in non-farm activities. This study expected that having internet access increase the probability of a households' participating in non-farm activities.

Table 1: Summary of Variable Definition and Measurement

\section{DEFINITION AND MEASUREMENT}

\begin{tabular}{|c|c|}
\hline Treat & 1 if the household has participated in non-farm activities, 0 if not. \\
\hline Fdinsec & $\begin{array}{l}\text { Number of times when at least one member of the household ate fewer meals a day than normal } \\
\text { ( } 2 \text { meals) due to lack of food accessibility (recall period of } 30 \text { days). }\end{array}$ \\
\hline \multicolumn{2}{|c|}{ EXPLANATORY VARIABLES: } \\
\hline Hhage & Age of household head at the time of interview in years. \\
\hline Hhsex & Taking the value of 1 if household head is a male, 0 otherwise. \\
\hline Hheduc & Number of years of schooling of household head after the first 14 years of birth. \\
\hline Conswr & Ratio of household members who work in the field to the household size. \\
\hline Dis_mkt & Distance from household's home to the nearest non-farm market in kilometers. \\
\hline Dis_mrd & Distance from household's home to main road in kilometers. \\
\hline Livstk & Number of cattle owned by a household. \\
\hline Landsz & Total land owned (agricultural plus residential in hectares). \\
\hline Asset & Total value of all productive fixed assets of a household. \\
\hline Credt & Taking the value of 1 if the household has taken credit in the past 12 month, 0 otherwise. \\
\hline Intrnt & Taking the value of 1 if the household has internet access, 0 if otherwise. \\
\hline
\end{tabular}

\subsection{Empirical Model of the Impact of Participation on Food Security}

The treatment/ impact evaluation model seeks to answer the second study research question to find the impact of households' participation in non-farm activities on rural farm households' food security status. The first step in the treatment evaluation model is to estimate the propensity scores for each household that participated in nonfarm activities (participants/ treated) and household that did not (Non-participants/ non-treated) based on the observable characteristics $\left(Z_{i}\right)$. The propensity score estimation is explained below.

\subsubsection{Propensity Scores Estimation}

The propensity scores are the probabilities of each individual in a sample to participate in non-farm activities given the household characteristics. These are important in treatment evaluation model as they enable the comparison of households with the same characteristics to minimise the self-selection bias into non-farm employment participation. According to Rosenbaum and Rubin (1983), the propensity scores are estimated using either the logit or probit model in case of binary treatments, which are in turn used to quantify the average treatment effect on the treated (ATET). The current study employed the logit model. The model specification for the propensity scores is the same as that of the logit model specified as:

$$
\operatorname{Prob}(z)=\operatorname{Prob}[L=1 \mid Z=z]
$$

Where $L=1$ is the observable treatment (participating in non-farm activities) and 0 otherwise; $Z$ is a vector of observable characteristics, which are exactly the same included in the logit model.

The purpose of the propensity scores are to search for the comparable counterfactual households among all non-participating households to form the control (counterfactual) group, and then compare the mean outcome of the participants against that of the non-participants. The underlying idea of the propensity score matching (PSM) is that the control and treatment households with the same or closest propensity score have the same probability of diversifying into non-farm employment activities, under randomized experiments which are then matched to reduce the self-selection bias (Tran et al., 2015). The propensity scores are used for matching two sample groups in the treatment evaluation model.

\subsubsection{Treatment Evaluation Model}

After the estimation of the propensity scores, the treatment evaluation model then compares the mean outcomes (food security status) of participants with that of the counterfactual group that did not participate. The impact of the households' participation in non-farm employment activities on rural households' food security status is examined using the treatment evaluation model, which compares, on average, the difference between the food security status outcome of the households who diversified into non-farm activities and those who did not. The treatment evaluation model is specified in equation 9:

$$
Y_{i}=\delta^{\prime} C_{i}+\alpha L_{i}+v_{i}
$$

where $C_{i}$ denote the set of variables same as in $Z_{i}$ which explain the household participation decision and 
hence $Y_{i}$ (household food security status) while $\delta^{\prime}$ is the vector of corresponding coefficients in the treatment evaluation model, $L_{i}$ has the same definition as above and $v_{i}$ is the treatment evaluation model error term.

Household food security status $\left(Y_{i}\right)$ in the treatment evaluation model specified in equation 9 is the dependent variable and was measured in terms of the number of times when at least one member of a household had fewer meals a day than normal ${ }^{1}$ due to lack of food accessibility. This measure of food security was adapted from Coates et al. (2007), which captures both the food availability and the accessibility in a household. Most of the subjective measures of food security only captures the food availability aspect of food security definition; hence, this measure is an improved measure (Coates et al., 2007). This measure of food insecurity is discrete (but count data) and will allow us to rank the households according to the severity of food insecurity of the households, where the households with higher number of times of having less than normal meals a day are considered to be relatively more food insecure.

The parameter of interest in equation (9) is:

$$
\begin{aligned}
& \hat{\alpha}=A T E T=E\left(Y_{1}-Y_{0} \mid Z\right) \\
& =E\left(Y_{1} \mid Z\right)-E\left(Y_{0} \mid Z\right) \\
& \hat{\alpha}=E\left(Y_{1} \mid Z, L=1\right)-E\left(Y_{0} \mid Z, L=0\right)
\end{aligned}
$$

which is the difference between the expected outcome ${ }^{2}$ of the participants $\left(Y_{1}\right)$ given a vector of explanatory variables $\left({ }^{Z}\right)$ and that the household has participated in non-farm activities $(L=1)$ and the expected outcome of the counterfactual group $\left(Y_{0}\right)$ given a vector of explanatory variables $\left({ }^{Z}\right)$ and that the household did not diversify into non-farm employment activities $(L=0)$.

The treatment evaluation model has become a popular approach to estimate the average impact of an intervention (Caliendo and Kopeinig, 2008). This model estimates the difference between the outcome (food security status) of the households who participated in non-farm activities and those who did not participate. This difference in food security status after we have controlled for other explanatory variables is referred to as the average treatment effect on the treated (ATET). The treatment evaluation model is useful in experimental studies as it allows the researcher to make use of the existing data sources (primary cross sectional data), so that it is easy and quicker to implement than to look for the data on 'before' and 'after' an intervention which might not be available. More so, the treatment evaluation model does not consider the functional form linking the outcome (food insecurity status, in this case) to non-farm participation. This model also allows for the control of the likely self-selection bias on observable characteristics that may lead the household to diversify into non-farm activities (Caliendo and Kopeinig, 2008). In addition, the use of the associated propensity score matching (PSM) technique will reduce the bias attributable to both the observable and unobservable characteristics.

\subsubsection{Treatment Evaluation Model Assumptions}

There are three main treatment evaluation model assumptions that should be met when estimating a treatment evaluation model. These assumptions are the overlapping condition assumption, the balancing property condition and the conditional mean independence.

The Overlapping Condition (Matching) states that each element in the treated group must have the matching counterpart (twin) in the non-treated group with the same characteristics that is propensity score. This can be mathematically expressed as $0<\operatorname{Pr}(L=1 \mid Z)<1$. If the propensity score lies within this range, it means that all individuals in the treated group have twin partners in the non-treated group with the same or closest propensity scores. If $\operatorname{Pr}(L=1 \mid Z)=1$ it means that there is no one with characteristics $Z$ in the control group or there is no twin to be matched with in the non-treated group. If $\operatorname{Pr}(L=1 \mid Z)=0$ it means that there is no one with characteristic $Z$ in the treated group. For the treatment evaluation to be feasible, the data should conform to this assumption, otherwise it is not feasible.

The Balancing Property Condition states that for the individuals with the same propensity score, the treatment assignment should be random and should look identical in terms of the vector ${ }^{Z}$. Rosenbaum and Rubin (1983) recommends a treatment evaluation model that balances the confounding factors before looking at results for the estimated treatment evaluation model. Thus, we do not interpret the treatment evaluation model results before checking if the model has the balanced covariates (explanatory variables for the probability of participating in non-farm activities). The test checks if the distribution of the conditioning variables (pretreatment characteristics) is not different across the treated and non-treated groups in the matched samples. More so, this test helps to check if the selection bias (due to observable characteristics) has been eliminated or not. This satisfies the matching requirements for calculating average treatment effects. The study used the balance box plot to check for the balancing condition.

Conditional Mean Independence states that the outcomes (food security status) should be independent from

\footnotetext{
${ }^{1}$. According to Nyamwanza (2014), a typical food secure household in Mbire district have two meals a day.

${ }^{2}$. The average number of times when at least one member of a household ate fewer meals than normal.
} 
the treatment assignment $\left({ }^{L}\right)$ once we control for pre-treatment characteristics $(Z)$. Conditional from ${ }^{Z}$, the outcomes are independent from the treatment. The participation should not influence the distribution of the potential outcome. This can be mathematically expressed as $Y_{1}, Y_{0} \perp L \mid Z$ which means that that the outcome of an individual, whether being treated or not, should be independent or orthogonal to the treatment assignment given a vector of explanatory variables. If this assumption is not satisfied, it necessitates the estimation of the propensity scores, which are then used for matching to estimate the average treatment effect on the treated.

\subsection{Data Collection Procedures}

The study used the Cochran's (1977) formula to determine the sample size that came out to be 152 households. Simple random sampling was used to select two out of seventeen wards in Mbire district (Chapoto and Angwa). One-stage cluster sampling technique was then employed, where the population was divided into two clusters (two wards that is Chapoto and Angwa). Equal number of respondents were then randomly selected from each cluster since the two wards have almost the same number of households (Nyamwanza, 2014). The researcher collected the data from the rural household heads in Mbire district with the help of three research assistants who were trained on how to collect the data and knowledgeable about the research topic and objectives. On-spot checks for commission, completeness and omission errors were done during the interviews. Respondents were interviewed in their language, which is shona. After the data collection process, all the questionnaires were checked and edited for completeness and consistency. Data were then captured using excel to be used in STATA for analysis.

\section{Findings}

\subsection{Descriptive Statistics}

This section describes and summarises the data collected on the factors influencing the rural farm households' decision to participate in non-farm activities and the impact of the participation on food security. The independent variables are categorised into continuous and categorical variables.

\subsubsection{Descriptive Statistics for Continuous Variables}

Table 2 shows that on average household heads who participated in non-farm activities are younger than those who did not participate. The treated group has an average of 42 years against 47 for the non-treated group. More so, on average, the household heads who participated in non-farm activities have more schooling years than those who did not. Those who participated in non-farm activities have an average of 5 years of education after their primary education while those who did not participate have an average of 1 year of education after their primary education. The households who participated in non-farm activities have, on average, bigger household size of 7 members than those who did not participate with an average of 5 members per household. Both the treated and the non-treated groups have almost the same consumer to worker ratio of 2 . The households who did not engage in non-farm activities have relatively longer distance to the main road and to the nearest market.

The distances to the main road are $2.77 \mathrm{~km}$ and 8.497 respectively for the treated and non-treated groups. The distances to the nearest market are $3.881 \mathrm{~km}$ and $10.116 \mathrm{~km}$ for the treated and non-treated respectively. The households who diversified into non-farm activities have on average bigger livestock herds of 5 cattle than their counterparts who did not diversify into non-farm activities with an average of 1 cow/household. More so, the households who participated in non-farm activities have on average bigger land than their counterparts who did not participate. Those who participated have an average of 7.532 hectares, while those who did not participate in non-farm activities have an average of 5.783 hectares. Furthermore, the participants are, on average, wealthier than non-participants in terms of assets ownership. The participants have an average value of assets amounting to RTGS \$1071.271, while the non-participants have RTGS \$364.94².

\footnotetext{
${ }^{1}$ Equivalent to US\$428.51 using the official exchange rate at the time of interviews.

${ }^{2}$ Equivalent to US\$104.27 using the official exchange rate at the time of interviews.
} 
Table 2: Descriptive Statistics for Continuous Variables

\begin{tabular}{lccc|ccc}
\hline & \multicolumn{2}{c|}{ Treated } & Group (Participants) & \multicolumn{3}{c}{ Non-Treated (Non-Participants) } \\
\hline Obs & Mean & Std. Dev & Obs & Mean & Std. Dev. \\
\hline Hhage & 47 & 42.064 & 10.852 & 97 & 47.113 & 13.340 \\
Hheduc & 47 & 5.106 & 2.267 & 97 & 1.737 & 2.263 \\
Hhsz & 47 & 5 & 2 & 97 & 7 & 3 \\
Conswkr & 47 & 2.058 & 0.704 & 97 & 2.200 & 1.716 \\
Dis_mrd & 47 & 2.277 & 1.392 & 97 & 8.497 & 5.931 \\
Dis_mkt & 47 & 3.881 & 2.359 & 97 & 10.166 & 6.921 \\
Livstk & 47 & 5.000 & 4.188 & 97 & 1.000 & 1.674 \\
Landsz & 47 & 7.532 & 3.719 & 97 & 5.738 & 3.084 \\
Asset & 47 & 1071.27 & 1223.46 & 97 & 364.94 & 1918.86 \\
\hline
\end{tabular}

4.1.2 Descriptive Statistics for Categorical Variables

Table 3 shows that the proportion of females who participated $(4.3 \%)$ in non-farm activities is significantly lower than the proportion of females who did not participate (45.4\%) in non-farm employment activities. This means that males dominate the non-farm sector. More so, the proportion of the participants in non-farm activities who own cellphones (93.6\%) is much higher than in the non-participant group (50.5\%). The same applies in the internet access where $74.5 \%$ of the participants in non-farm activities have internet access while only $7.2 \%$ of the non-participant group have internet access. In addition, the proportion of the households who have access to credit $(40.4 \%)$ is relatively higher in the treated group than in the non-treated group of $2.1 \%$.

The food insecurity variable had discrete values ranging from 0 to 22 . In Table 3 , the variable was split into 3 categories depending on severity: severely food insecure (15-22), moderately food-insecure (8-14) and less food-insecure (0-7). As shown in Table 3,100\% of the treated group were less food insecure. In the non-treated group, $10 \%$ of the respondents were severely food insecure, while $74.2 \%$ were moderately food-insecure and $16.5 \%$ were less food insecure. This means that the respondents who did not diversify into non-farm employment activities are generally more food-insecure relative to those who diversified, ceteris paribus.

Table 3: Descriptive Statistics of Discrete Variables

\begin{tabular}{|c|c|c|c|c|c|c|c|c|}
\hline & \multicolumn{4}{|c|}{ Treated Group (Participants) } & \multicolumn{4}{|c|}{ Non-Treated Group (Non-Participants) } \\
\hline Variable & \multirow[t]{2}{*}{ Prop } & \multirow[t]{2}{*}{ Std.Err. } & \multicolumn{2}{|c|}{ [95\%Co Interval] } & \multirow[t]{2}{*}{ Prop } & \multirow[t]{2}{*}{ Std.Err. } & \multicolumn{2}{|c|}{ [95\%Conf Interval] } \\
\hline Hhgendr & & & & & & & & \\
\hline Females & 0.043 & 0.030 & 0.010 & 0.162 & 0.454 & 0.051 & 0.356 & 0.555 \\
\hline Males & 0.957 & 0.030 & 0.838 & 0.990 & 0.546 & 0.051 & 0.445 & 0.644 \\
\hline Celphn & & & & & & & & \\
\hline No Cell & 0.064 & 0.036 & 0.020 & 0.187 & 0.495 & 0.051 & 0.395 & 0.595 \\
\hline Owners & 0.936 & 0.036 & 0.813 & 0.980 & 0.505 & 0.051 & 0.405 & 0.605 \\
\hline Intrnt & & & & & & & & \\
\hline No Acc & 0.255 & 0.064 & 0.148 & 0.404 & 0.928 & 0.026 & 0.855 & 0.966 \\
\hline Access & 0.745 & 0.064 & 0.596 & 0.852 & 0.072 & 0.026 & 0.034 & 0.145 \\
\hline Credt & & & & & & & & \\
\hline No Acc & 0.596 & 0.072 & 0.446 & 0.730 & 0.979 & 0.015 & 0.919 & 0.995 \\
\hline Access & 0.404 & 0.072 & 0.270 & 0.554 & 0.021 & 0.015 & 0.005 & 0.081 \\
\hline Fdinsec & & & & & & & & \\
\hline Severe (15-22) & 0.000 & 0.000 & - & - & 0.093 & 0.03 & 0.048 & 0.171 \\
\hline Moderate (8-14) & 0.000 & 0.000 & - & - & 0.742 & 0.045 & 0.644 & 0.821 \\
\hline $\operatorname{Less}(0-7)$ & 1.000 & 0.000 & - & - & 0.165 & 0.038 & 0.103 & 0.254 \\
\hline
\end{tabular}

\subsection{Econometric Results}

\subsubsection{Factors influencing Rural Households' Participation in Non-Farm Employment}

Table 4 presents the results from the logistic regression estimation. The coefficients of the logistic regression estimation only provides the sign of change but not the magnitude of change. Interpreting these coefficients inflates the impact since the model is non-linear. The way to interpret the results from the maximum likelihood estimations (logistic in this case) is to estimate the marginal effects, which gives both the impact and the direction. Marginal effect is the actual effect of a unit change in each regressor on the participation decision probability. Table 6 presents the average marginal effects (AME) from the logistic regression estimation. 
Table 4: Logistic Regression Results

\begin{tabular}{lcccccc}
\hline Treat & Coef. & Std.Err. & $\mathbf{Z}$ & P $>\mathbf{Z}$ & [95\%Conf. & Interval] \\
\hline Hhgendr & $2.607^{*}$ & 1.379 & 1.890 & 0.059 & -0.095 & 5.309 \\
Intrnt & $2.628^{* *}$ & 1.087 & 2.420 & 0.016 & 0.496 & 4.759 \\
Dis_mrd & $-0.568^{* *}$ & 0.274 & -2.070 & 0.038 & -1.105 & -0.031 \\
Livestock & $0.843^{* * *}$ & 0.281 & 3.000 & 0.003 & 0.293 & 1.393 \\
Hheduc & $0.513^{* * *}$ & 0.185 & 2.770 & 0.006 & 0.150 & 0.877 \\
Hhage & 0.078 & 0.241 & 0.320 & 0.747 & -0.394 & 0.550 \\
Hhage2 & -0.001 & 0.002 & -0.470 & 0.637 & -0.006 & 0.004 \\
Asset & $-0.047^{* *}$ & 0.020 & -2.430 & 0.015 & -0.086 & -0.009 \\
Dis_mkt & -0.037 & 0.145 & -0.250 & 0.800 & -0.320 & 0.247 \\
Landsz & $-4.105^{*}$ & 2.431 & -1.690 & 0.091 & -8.870 & 0.661 \\
Credt & 2.762 & 1.860 & 1.490 & 0.138 & -0.883 & 6.408 \\
Cons & -4.495 & 6.106 & -0.740 & 0.462 & -16.463 & 7.472 \\
\hline
\end{tabular}

Number of obs = 144, LR Chi2(11) = 139.32, Prob $>$ Chi2 $=0.000$, Log likelihood $=-21.2915$

$* * *$ represent $1 \%, * *$ represent $5 \%$ and $*$ Presents $10 \%$ level of significance

The statistical significance of the regressors was tested using the p-value of the t-statistic. The nullhypothesis states that; the demographic, infrastructural and farm level characteristics have no significant effect on a rural farm households' decision to participate in non-farm activities. The null hypothesis was rejected when the p-value was found to be less than the conventional levels of significance $(1 \%, 5 \%$ and $10 \%)$. Several coefficients of the explanatory variables were found to be statistically significant, which are interpreted after the estimation of the marginal effects. The insignificant coefficients are not interpreted.

Table 5: Average Marginal Effects from the Logistic Regression

\begin{tabular}{lclllll}
\hline & dy/dx & Std.Err. & $\mathbf{Z}$ & $\mathbf{P}>\mathbf{Z}$ & [95\%Conf & Interval] \\
\hline Hhgendr & $0.112^{* *}$ & 0.056 & 1.980 & 0.047 & 0.001 & 0.222 \\
Intrnt & $0.113^{* * *}$ & 0.043 & 2.630 & 0.008 & 0.029 & 0.196 \\
Dis_mrd & $-0.024^{* *}$ & 0.011 & -2.240 & 0.025 & -0.046 & -0.003 \\
Livestock & $0.036^{* * *}$ & 0.010 & 3.520 & 0.000 & 0.016 & 0.056 \\
Hheduc & $0.022^{* * *}$ & 0.007 & 3.110 & 0.002 & 0.008 & 0.036 \\
Hhage & 0.003 & 0.010 & 0.320 & 0.748 & -0.017 & 0.024 \\
Hhage2 & -0.000 & 0.000 & -0.470 & 0.638 & -0.000 & 0.000 \\
Asset & $-0.002^{* * *}$ & 0.001 & -2.740 & 0.006 & -0.003 & -0.001 \\
Dis_mkt & -0.002 & 0.006 & -0.250 & 0.800 & -0.014 & 0.011 \\
Landsz & $-0.176^{*}$ & 0.102 & -1.730 & 0.083 & -0.375 & 0.023 \\
Credt & 0.118 & 0.079 & 1.500 & 0.134 & -0.036 & 0.273 \\
\hline
\end{tabular}

$D y / d x$ is for a unit change of the explanatory variable, discrete change from 0 to 1 for a dummy. *** represent 1\%,** represent 5\% and * Presents $10 \%$ level of significance

The coefficient of gender of the household head was positive and statistically significant at $5 \%$ level. This is in tandem with the a priori expectation that being a male increases the probability of a household to engage in non-farm activities by $11.2 \%$. This is because men are generally stronger enough to handle the strenuous nonfarm activities carried out in Mbire district than their female counter parts. Few women can only handle nonfarm activities such as gold panning and itinerant trading. Yesuf (2015) got the similar results in Ethiopia.

Regarding the access to internet, the coefficient of internet access is positive and statistically significant at $1 \%$ level. Having access to internet increases the probability of the household to participate in non-farm employment activities by $11.3 \%$. This holds true because a household with access to internet has relatively more access to non-farm employment opportunities, mainly via social media such as WhatsApp.

Supporting the results by Tsiboe et al. (2016), the coefficient of the distance from the farm to the main road was negative and statistically significant at 5\% level. An increase in the distance to the main road by a kilometer reduces a household's probability to diversify into non-farm activities by $2.4 \%$. This is justified since the major non-farm activity in the study area is itinerant trading; traders need to travel by public transport so walking long distance to the main road is quite discouraging and very tiresome.

The coefficient of livestock holding in the model was positive and statistically significant at $1 \%$ level. A unit increase in a cattle herd increases the household's chance to participate in non-farm activities by $3.6 \%$. This is because livestock eases smallholder farmers' liquidity constraint. Livestock are liquid in the rural areas. Yesuf (2015) used the same variable in the non-farm employment model and found the same results.

The coefficient of education level of the household head is statistically significant at $1 \%$ level meaning that education is a determinant of the rural households' participation in the non-farm sector, particularly in non-farm wage employment. The study shows that having some levels of education is associated with the higher 
probability of participating in non-farm activities. One-year increase in post primary years of education of a household head increases the chance of the household to participate in non-farm activities by $2.2 \%$. This is because educated people look for less strenuous employment in the non-farm sector. In Mbire district, educated people are employed by the Grain Marketing Board (GMB) and by the Public Service Commission mainly as teachers and police officers. Matshe and Young (2004) used this variable in their non-farm labour allocation decision in Shamva and got the similar results.

The coefficient of assets ownership was negative and statistically significant at $1 \%$ level. A unit increase in the value of household assets decreases the probability of the household's participation in non-farm activities by $0.2 \%$. This is contrary to the study hypothesis and to the results gotten by Tran et al. (2015). This is possibly because of households with more assets are more productive, hence food self-sufficient causing them not to be much involved in non-farm employment activities.

The study found the coefficient of the households' land size to be negative and statistically significant at $10 \%$ level. This means that a unit increase in household's land reduces the probability of that household to participate in non-farm activities by $17 \%$. This is so possibly because large farms in Mbire district are more productive than small farms, hence households occupying large pieces of land are food self-sufficient then reducing their probability of participating in non-farm activities.

\subsubsection{Impact of Participation in Non-Farm Employment on Households' Food Security}

The study employed the treatment evaluation model and the propensity scores matching (PSM) to quantify the impact of the decision to participate in non-farm activities on rural households' food security. Table 6 shows the results from the treatment evaluation using the PSM.

Table 6: Treatment Evaluation Using the PSM

\begin{tabular}{|c|c|c|c|c|c|c|}
\hline Fdinsec & Coef. & St.Err. & t-value & p-value & {$[95 \%$ Conf } & Interval] \\
\hline $\begin{array}{l}\text { ATET } \\
\text { (Treated < Non-Treated) }\end{array}$ & $-4.285 *$ & 2.412 & -1.78 & 0.076 & -9.012 & 0.443 \\
\hline
\end{tabular}

The dependent variable was measured as the number of times when at least one member of the household member(s) ate fewer meals per day than usual due to lack of food accessibility. The estimate of the average treatment effect on the treated (ATET) in table 7 is -4.285 . This means that, on average, participation in nonfarm activities reduce food insecurity by 4.285 times. This outcome is in tandem with the findings of Dabalen et al. (2004) who found the same results in rural Rwanda and Tsiboe et al. (2016) in Northern Ghana. These studies employed a similar estimation technique to investigate the impact of participation in non-farm activities on rural farm households' food security status.

\section{Conclusions}

The study sought to investigate the factors influencing the rural households' decision to participate in non-farm activities and the impact of participation in non-farm activities on rural households' food security status using sample data collected from Mbire district of Mashonaland Central of Zimbabwe. The study identified factors such as household head gender, internet access, distance to the main road, livestock ownership, household head education attainment, land size and ownership of assets such as motorbikes, trucks, and scotch carts and ploughs as significant determinants of non-farm activity participation. The propensity score matching (PSM) technique was employed to eliminate the possible self-selection bias emanating from observable and unobservable factors that influence the rural households' decision to participation in non-farm activities. The rural households' food security was measured by the number of times when at least one member of the household had to eat fewer meals than normal, using a recall period of 30 days. The matching result from the treatment effects results shows that participation in non-farm activities have a positive and statistically significant impact on the rural households' food security status. This finding is consistent with the widely held view in the literature that nonfarm income plays a pivotal role to improve their food security-status.

The findings of this study suggest that participation in non-farm activities could be a pathway/coping strategy to improve rural households' food security status in Mbire district and other areas sharing the same characteristics in developing countries. Any policies targeted at promoting rural household food security should go beyond just crop production measures; they should address both the crop production measures and measures that help generate additional incomes for rural farm households by promoting non-farm activities. This study is not advocating for non-farm activities as a substitute to farming, but as a reliable complement to farming activities, therefore policymakers should aim to promote rural households' participation in non-farm activities by increasing the access of rural households to physical, financial and human capital. Physical capital, which include good roads and general infrastructural development, will help to reduce transportation costs therefore easing the barriers to non-farm participation and enhance non-farm income leading to reduced food-insecurity.

Opportunities to work in the non-farm sector can also be enhanced by improving access to post-primary education in rural communities. Given that female-headed households normally face the entry barriers, policy 
measures could target them to increase their chance to diversify into non-farm activities that would improve their food security. More so, there should be provision of light non-farm jobs for women like poultry and dress making to alleviate food insecurity among female-headed households. Promising policy measures that can help boost non-farm activities also include increasing the access of rural households to education and infrastructure.

The results imply that policy must focus on promoting non-farm employment opportunities in rural farming communities, given its positive impact on food security and incomes.

\section{References}

Amemiya, T. 1985. Advanced Econometrics, Harvard U. Press, Cambridge.

Babatunde, R.O. and Qaim, M., 2010. Impact of Non-farm Income on Food Security and Nutrition in Nigeria. Food Policy, 35(4), 303-311.

Caliendo, M. and Kopeinig, S., 2008. Some Practical Guidance for the Implementation of Propensity Score Matching. Journal of Economic Surveys, 22(1), 31-72.

Cameron, A.C and Trivedi, P.K., 2007: Microeconometrics, STATA Press.

Chayanov, A. V., 1966. The Theory of Peasant Economy. The University of Chicago Press, Chicago.

Coates, J., Swindale, A. and Bilinsky, P., 2007. Household Food Insecurity Access Scale (HFIAS) for measurement of food access: indicator guide. Washington, DC: food and nutrition technical assistance project, academy for educational Development, 34.

Cochran, W.G., 1977. The Estimation of Sample Size. Sampling Techniques, 3, 72-90.

Dabalen, A., Paternostro, S. and Pierre, G., 2004. The Returns to Participation in the Non-Farm Sector in Rural Rwanda (Vol. 3462). World Bank Publications.

Fei, J.C. and Ranis, G., 1964. A Theory of Economic Development. The American Economic Review, 533-565.

Fritz, H., Saïd, S., Renaud, P.C., Mutake, S., Coid, C. \& Monicat, F., 2003. The Effects of Agricultural Fields and Human Settlements on the Use of Rivers by Wildlife in the Mid-Zambezi Valley, Zimbabwe. Landscape Ecology 18, 293-302.

Kinuthia, B.K., Maende, S., Baraza, L. and Mariera, F., 2018. Non-farm Participation, Agricultural Production and Farmers Welfare in East Africa. University of Nairobi.

Lewis, W.A., 1954. Economic Development with Unlimited Supplies of Labour. The Manchester School, 22(2), 139-191.

Matshe, I. and Young, T., 2004. Off - Farm Labour Allocation Decisions in Small - Scale Rural Households in Zimbabwe. Agricultural Economics, 30(3), 175-186.

Mishra, A. and Rahman, A., 2018. Does Non-farm Income Affect Food Security? Evidence from India.

Nyamwanza, A., 2014. Bridging Policy and Practice for Livelihood Resilience in Rural Africa: Lessons from the Mid-Zambezi Valley, Zimbabwe. The Journal of Rural and Community Development, 9(4), 23-33.

Owusu, V., Abdulai, A. and Abdul-Rahman, S., 2011. Non-Farm Work and Food Security among Farm Households in Northern Ghana. Food Policy, 36(2), 108-118.

Pfeiffer, L., López - Feldman, A. and Taylor, J.E., 2009. Is Off - Farm Income Reforming the Farm? Evidence from Mexico. Agricultural Economics, 40(2), 125-138.

Rosenbaum, P.R. and Rubin, D.B., 1983. The Central Role of the Propensity Score in Observational Studies for Causal Effects. Biometrika, 70(1), 41-55.

Sen, A., 1982. Poverty and Famines: An Essay on Entitlement and Deprivation. Oxford University Press.

Seng, K., 2015. The Effects of Nonfarm Activities on Farm Households' Food Consumption in Rural Cambodia. Development Studies Research, 2(1), 77-89.

Shehu, A. and Sidique, S.F., 2013. A Propensity Score Matching Analysis of the Impact of Participation in NonFarm Enterprise Activities on Household Wellbeing in Rural Nigeria. UMK Procedia, 1, 26-32.

Singh, I., Squire, L. and Strauss, J., 1986. Agricultural Household Models: Extensions, Applications, and Policy. The World Bank.

Tran, T.Q., Nguyen, S.H., Vu, H.V. and Nguyen, V.Q., 2015. A Note on Poverty among Ethnic Minorities in the Northwest Region of Vietnam. Post-Communist Economies, 27(2), 268-281.

Tsiboe, F., Zereyesus, Y.A. and Osei, E., 2016. Non-Farm Work, Food Poverty, and Nutrient Availability in Northern Ghana. Journal of Rural Studies, 47, 97-107.

World Food Summit 1996, Rome Declaration on World Food Security.

Yesuf, M., 2015. Factors Affecting Participation of Rural Households in Non-farm Activities in Tigray National Regional State, 4(7), 1066-1080.

Zimbabwe Vulnerability Assessment Committee (ZIMVAC), 2018, Zimbabwe rural food security assessment national report, Government of Zimbabwe, Harare. 